\title{
PRÁXIS PRODUTIVA, METAMORFOSES NO MUNDO DO TRABALHO E PROCESSO DE CONSTITUIÇÃO DE IDENTIDADE ENTRE TRABALHADORES
}

\author{
NA AMAZÔNIA PARAENSE'
}

Raimundo Nonato Gaia Correa ${ }^{2}$

Doriedson do Socorro Rodrigues ${ }^{3}$

Ronaldo Marcos de Lima Araújo ${ }^{4}$

\begin{abstract}
Resumo
O texto objetiva responder como ocorre a relação entre práxis produtiva e processos de constituição de identidade de pescadores artesanais. Faz-se uso de revisões bibliográficas e entrevista semiestruturada e os dados foram analisados à luz do Materialismo Histórico-Dialético. Após os impactos ambientais da UHE-Tucuruí os pescadores dedicam-se ao manejo do açaí e dos recursos pesqueiros. A venda do açaí para exportação facilita a inserção do capital em sua práxis produtiva, mas gestão coletiva e repartição igualitária do pescado nos Acordos de Pesca corrobora para a constituição de sua identidade numa perspectiva contra hegemônica.
\end{abstract}

Palavras-chave: Práxis produtiva; contradições entre capital e trabalho; pescadores artesanais; identidade.

\section{PRODUCTIVE PRAXIS, METAMORPHOSES IN THE WORLD OF LABOR AND PROCESS OF CONSTITUTION OF IDENTITY AMONG WORKERS IN THE PARAENSE AMAZON}

\begin{abstract}
The text aims to answer how the relationship between productive praxis and processes of identity formation of artisanal fishers occurs. It was used bibliographical reviews and semi-structured interviews and the data were analyzed in the light of Historical-Dialectical Materialism. After the environmental impacts of UHE-Tucuruí fishermen dedicate themselves to the management of açai and the fishing resources. The sale of açai for export facilitates the insertion of capital into its productive praxis, but collective management and equal distribution of fish in the Fisheries Agreements corroborates for the constitution of its identity in a counter-hegemonic perspective.
\end{abstract}

Keywords: Productive praxis; contradictions between capital and labor; artisanal fishermen; identity.

1DOI: https://doi.org/10.22409/tn.16i31.p27385

${ }^{2}$ Mestre em Educação e Cultura (UFPA). Pesquisador do Grupo de Estudos e Pesquisas sobre Trabalho e Educação - GEPTE/UFPA. E-mail: r.nonatog@hotmail.com.

${ }^{3}$ Doutor em Educação. Docente do Programa de Pós-Graduação em Educação e Cultura (PPGEDUC/UFPA) e do Programa de Pós-Graduação em Currículo e Gestão da Escola Básica (PPEB/UFPA). Membro do Grupo de Estudos e Pesquisas sobre Trabalho e Educação GEPTE/UFPA. E-mail: doriedson@ufpa.br

${ }^{4}$ Doutor em Educação. Docente do Programa de Pós-Graduação em Currículo e Gestão da Escola Básica (PPEB/UFPA). Coordenador do Grupo de Estudos e Pesquisas sobre Trabalho e Educação GEPTE/UFPA.E-mail:rlima@ufpa.br. 


\section{Introdução}

O artigo expõe parte dos resultados de pesquisa e versa sobre a relação entre práxis produtiva e processos de constituição de identidade entre pescadores artesanais da Amazônia Paraense, adotando como lócus de pesquisa a Colônia Z16. Essa entidade tem sede localizada na cidade de Cametá, Estado do Pará, mas se faz presente em quase todas as comunidades ribeirinhas do município, uma vez que conta com 91 coordenações de base e um total de 15.087 pescadores/as associados/as ${ }^{4}$.

Numa breve revisão de literatura, observamos alguns estudos de pesquisadores ligados ao Campus da UFPA de Cametá, sobretudo do Grupo de Estudos e Pesquisas sobre Trabalho e Educação da Universidade Federal do Pará, que vêm dando ênfase à relação entre trabalho e educação no contexto da organização dos pescadores artesanais de Cametá 5 .

Rodrigues (2012) analisou a relação entre os saberes sociais e a materialidade de luta de classes experienciada pelos pescadores artesanais da Colônia Z-16 frente aos interesses antagônicos do capital, personificado na região por meio da UHE-Tucuruí e das elites econômico-políticas.

Martins (2017) constatou que os pescadores da Z-16 materializam relações de produção-formação e, integradamente, constituem uma práxis política que se contrapõe à lógica da classe dominante. Em outro momento, Martins (2011) havia analisado a relação entre o saber produzido pelo trabalho dos pescadores artesanais e a participação política desses sujeitos no contexto social de seus movimentos.

Barra (2013) analisou os Acordos de Pesca enquanto formas estratégicas para a gestão dos recursos pesqueiros e como mecanismo capaz de fomentar a organização coletiva entre os pescadores artesanais. Adenil Rodrigues (2016)

\footnotetext{
${ }^{4}$ Fundada na década de 1920, esta entidade só recentemente (início dos anos 1990) passou a ser conduzida por gestores que se constituem pescadores artesanais, uma vez que desde sua fundação "[...] não estava sob a gestão dos pescadores, mas sim sob os auspícios de sujeitos não pescadores ligados aos interesses das oligarquias locais [...]" (RODRIGUES, 2012, p. 257).

${ }^{5} \mathrm{O}$ município de Cametá, segundo o IBGE (2010), pertence à mesorregião do nordeste paraense e à microrregião Cametá, apresenta uma área correspondente a $3.122 \mathrm{~km}^{2}$. Limita-se ao norte com o município de Limoeiro do Ajuru; ao sul, com o de Mocajuba; a leste, com o de Igarapé-Miri; e a oeste, com o de Oeiras do Pará. Trata-se de um município com contingente rural maior do que o urbano.
} 
problematizou se os jovens pescadores egressos de um curso técnico de aquicultura utilizam os conhecimentos adquiridos em correlação com os saberes produzidos e aprendidos no cotidiano da pesca como elementos de formação da identidade pescadora.

Pompeu (2017) analisou a organização coletiva dos pescadores artesanais como mecanismo de enfrentamento aos impactos da UHE-Tucuruí, mas também observou um distanciamento do trabalho da pesca de uma perspectiva de produção de valores de uso. E Furtado (2017) concluiu que as práticas e saberes das mulheres pescadoras ainda se limitam ao espaço dos afazeres domésticos em detrimento da participação política em organizações de classe.

Em termos metodológicos este estudo pauta-se em revisões bibliográficas e pesquisa de campo. Os dados empíricos foram coletados por meio de entrevista semiestruturada $^{6}$ (PÁDUA, 2012) e as análises foram estruturadas a partir da dialética singular-particular-universal de Lukács (1978), entendendo-se que os fenômenos sociais não se limitam à expressão imediata e factual, mas vinculam-se, por uma série de mediações, às leis gerais que condicionam o funcionamento da sociedade capitalista como uma totalidade (KOSIK, 1976).

O texto apresenta três seções. Numa primeira, analisa-se o processo de constituição do ser social pescador artesanal em meio as relações que estruturam sua práxis produtiva, no âmbito da qual se constitui a identidade dessa fração de classe, desde um ponto de vista ontológico.

Na segunda seção discute-se a mediação exercida pelo capital na dinâmica de produção da existência dos pescadores artesanais, em particular o projeto de desenvolvimento capitalista para a Amazônia Paraense que tem como objetivo utilizar o potencial hídrico do rio Tocantins ${ }^{7}$ para produção de energia elétrica, donde se observou consequências negativas para a pesca artesanal, impactos ambientais decorrentes da construção da Hidrelétrica e a precarização das condições de trabalho e de vida dos pescadores.

\footnotetext{
${ }^{6}$ Os pescadores entrevistados serão nomeados de maneira fictícia para preservar suas identidades, conforme fizemos na dissertação de mestrado. Aparecerão no corpo do texto como: Pescador P1; P2; P3; P4; P5; P6; e P7.

${ }^{7}$ Segundo o IBGE (2018), "o Rio Tocantins, que atravessa os estados de Goiás, Tocantins, Pará e Maranhão, tem uma área de 803.200 quilômetros quadrados, sua extensão de 2.416 quilômetros. É muito utilizado para navegação fluvial. Nele estão instaladas grandes usinas hidrelétricas, sendo a principal a Usina Hidrelétrica de Tucuruí.
} 
$\mathrm{Na}$ terceira seção debate-se as alternativas produtivas criadas pelos pescadores artesanais e seus desdobramentos para o processo de constituição identitária desses sujeitos - processo esse que vem sofrendo a interferência do antagonismo entre capital e trabalho e, por conseguinte, a identidade que daí resulta caracteriza-se como uma unidade de contrários. Em seguida apresentamos as considerações finais.

\title{
Práxis produtiva e constituição da identidade do ser social pescador artesanal
}

Partindo do Materialismo Histórico Dialético (LUKÁCS, 2013), entende-se que é por meio do trabalho ${ }^{8}$ que o homem estabelece com a natureza uma relação consciente, na medida em que todos os atos do primeiro dirigidos para a transformação da segunda são orientados por fins conscientemente prefigurados.

Lukács (2013), ao colocar o trabalho como fundamento ontológico de constituição do homem, caracteriza esta atividade especificamente humana como pôr teleológico, no sentido de que não se trata de uma tomada de consciência à posteriori de um ato prático que ocorre à revelia das faculdades mentais, mas de um ato que implica o pensar (o projetar) com o agir, em uma palavra, uma ação na qual imbricam-se a atividade intelectual e a atividade material.

\begin{abstract}
Pôr, nesse contexto, não significa, portanto, um mero elevar-àconsciência, como acontece com outras categorias e especialmente com a causalidade; ao contrário, aqui, com o ato de pôr, a consciência dá início a um processo real, exatamente o processo teleológico. Assim, o pôr tem, nesse caso, um caráter irrevogavelmente ontológico (LUKÁCS, 2013, p. 48).
\end{abstract}

\footnotetext{
${ }^{8}$ Neste artigo, a partir de Vázquez (2011), entende-se práxis produtiva e produção da vida material como sinônimos, e que dizem respeito à forma de objetivação humana, por meio do trabalho, levada a efeito para produzir valores de uso. Em termo de práxis produtiva, partimos da compreensão de Vázquez (2011) que a compreende como "[...] a atividade prática produtiva, ou relação material e transformadora que o homem estabelece - mediante seu trabalho - com a natureza. Graças ao trabalho, o homem vence a resistência das matérias e forças naturais e cria um mundo de objetos úteis que satisfazem determinadas necessidades" (VÁZQUEZ, 2011, p. 228). Nessa perspectiva teórica, a práxis produtiva se materializa por meio da relação que o homem estabelece com a natureza no processo de transformação dos recursos naturais nos bens úteis que satisfazem suas necessidades de alimentação, abrigo, locomoção, etc.
} 
Pode-se dizer que o ser humano singular, como ser natural, para se reproduzir como homem, tem de produzir sua própria existência, processo que é mais bem caracterizada como um salto do que como evolução. Segundo Marx (2013, p. 255), ao colocar em movimento seus braços, pernas, cabeça e mãos, "[...] agindo sobre a natureza externa e modificando-a por meio desse movimento, ele [homem] modifica, ao mesmo tempo, sua própria natureza".

Assim, autoprodução do ser social só é possível na medida em que os homens singulares entram em determinadas relações de produção uns com os outros. Dessa forma, o trabalho é o elemento mediador que está na base da constituição concomitante do homem singular e da sociedade, de modo que a relação indivíduo-sociedade é uma relação de autodeterminação.

Com isso, é possível dizer que a partir do momento em que estabelecem relações entre si, quando produzem a sociedade e a si mesmos, os homens deixam se ser meras singularidades (como membros naturais de uma espécie que viria a ser espécie humana) para se autoproduzirem como individualidades (seres humanos que atuam conscientemente em sociedade).

O modo de manifestação, o órgão dessa nova forma de reprodução dos seres humanos tornada social é seu modo de ser como individualidades. A singularidade meramente natural (biológica) do homem singular correspondia ao estágio da reprodução biológica espontânea, superado, em princípio, pelo trabalho (LUKÁCS, 2010, p. 89-90).

Em síntese, pode-se dizer que a formação ontológica do ser social obedece à dialética singularidade-particularidade-universalidade, conforme sumaria Lukács (1978, p. 93), apoiado em Marx:

Deve-se evitar, sobretudo, fixar a "sociedade" como uma abstração em face do indivíduo. O indivíduo é ente social. A sua manifestação de vida - mesmo que não apareça na forma direta de uma manifestação de vida comum, realizada ao mesmo tempo com outros - é, portanto, uma manifestação de uma afirmação de vida social. A vida individual e a vida genérica do homem não são distintas, ainda que - necessariamente - o modo de existência da vida individual seja um modo mais particular ou mais geral da vida individual. 
Nestes termos, a formação do ser social ocorre no processo de produção dos bens materiais indispensáveis à sobrevivência humana (universalidade). Essa autoprodução humana efetiva-se por meio do trabalho de indivíduos humanos singulares (singularidade) produzindo suas existências sob relações de produção, distribuição, troca e consumo que particularizam um determinado contexto histórico e social (particularidade). Esse processo é descrito por Marx (2011) como relação geral entre produção, distribuição, troca e consumo.

A produção cria os objetos correspondentes às necessidades; a distribuição os reparte segundo leis sociais; a troca reparte outra vez o já repartido, segundo a necessidade singular; finalmente, no consumo, o produto sai desse movimento social, devém diretamente objeto e serviçal da necessidade singular e a satisfaz no desfrute (MARX, 2011, p. 44).

Sob a compreensão de que a constituição do ser social ocorre em concomitância com o processo de transformação da natureza pelo ser humano, busca-se analisar a relação entre práxis produtiva e processos de constituição da identidade dos pescadores artesanais da Colônia Z-16.

Consideramos que, em termos empíricos, a pesquisa realizada no contexto da Colônia Z-16 nos permite inferir que o pescador artesanal se autoproduz como individualidade por meio das relações constitutivas do mundo do trabalho. Segundo Lukács (2010), o homem, como um mero ser biológico (singularidade natural), só se torna um ser propriamente humano (individualidade) quando estabelece relações com outros homens (sociedade) por meio da práxis produtiva.

Conforme depoimentos dos sujeitos entrevistados, verifica-se que a singularidade se constitui como individualidade pescador artesanal, ao logo da história, na mediação da atividade produtiva da pesca compartilhada socialmente entre as gerações de pescadores artesanais. "Eu comecei na pesca com o meu pai, de piloto ${ }^{9}$, aí depois já passei para ir jogando rede, daí ficou a rede pra mim, depois meu pai 'foi embora'10 e vendemos a rede. Depois, e eu já comprei a minha" (PESCADOR P3).

\footnotetext{
${ }^{9} \mathrm{O}$ piloto é aquele que conduz as embarcações de pesca (ou cascos de rede), geralmente à remo. ${ }^{10}$ Alusão ao falecimento.
} 
O trabalho da pesca é transmitido de geração para geração no próprio ato de pescar e, assim, novos pescadores artesanais vão se (auto) produzindo, perpetuando a atividade pesqueira artesanal, conforme esclarece a fala do entrevistado a seguir: "os meus filhos eu levo comigo para pescar desde criança. Vão logo aprendendo. Todos sabem pescar" (PESCADOR P3).

Como a constituição do homem é um processo social, compreende-se que a formação social do pescador artesanal é mediada por essas relações de aprendizado das atividades produtivas. Vygotsky (2007) postulava que a constituição do pensamento, da ação e da consciência acontece nas relações concretas da vida social, no estágio em que o aspecto cultural, socialmente construído, sobrepõe-se ao aspecto biológico da criança em formação. Esse processo é puramente social, na medida em que os atos que medeiam a relação da criança com o meio são interpretados e acrescidos de significados pelos adultos que a cercam. Assim, [...] "o caminho do objeto até a criança e desta até o objeto passa através de outra pessoa" (VYGOTSKY, 2007, p. 20).

Mas os dados nos mostram que não só na pesca pode ser visualizada a formação social do pescador artesanal. No trabalho agrícola com o açaí ${ }^{11}$, também a mediação do adulto é fundamental para que a criança possa aprender um dos ofícios que está na base de seu processo de socialização:

Eu tenho é dois pedacinhos de terra que é da minha família, porque é dos 4 filhos que eu tenho. Lá que a gente mora, é pra onde eu levo as crianças pra gente apanhar o açaí, ir limpando, cuidando das coisas, né, de lá a gente tira açaí pra beber, pra vender e ir arrumando uma comidinha pra se comer e ir vivendo, né (PESCADOR P2).

Nessa perspectiva, pode-se dizer que a formação social do pescador artesanal, de acordo com os dados empíricos e dos postulados Vygotskyanos, é mediada pelas relações de aprendizagem que as crianças estabelecem com os

$11 \mathrm{O}$ açaizeiro (Euterpe oleracea Mart.) é nativo da Amazônia brasileira e o estado do Pará é o principal centro de dispersão natural dessa palmácea. $O$ açaizeiro se destaca, entre os diversos recursos vegetais, pela sua abundância e por produzir importante alimento para as populações locais. Dos frutos do açaizeiro são extraídos o vinho e a polpa. O açaí é habitualmente consumido com farinha de mandioca, associado ao peixe, camarão ou carne, sendo o alimento básico para as populações de origem ribeirinha. Com o açaí são fabricados sorvetes, licores, doces, néctares e geleias, podendo ser aproveitado, também, para a extração de corantes e antocianina (NOGUEIRA, 2005, pp. 11-12). 
pescadores adultos. A práxis produtiva revela-se como um tempo-espaço de ensinoaprendizagem por excelência, e por meio do qual as crianças, ao serem inseridas no exercício das atividades produtivas, vão se autoproduzindo como seres sociais pescadores artesanais.

Nessa perspectiva, observa-se que o processo de formação do ser social pescador artesanal está na base da constituição de sua identidade ${ }^{12}$. Trata-se de um processo intrinsecamente relacionado ao mundo do trabalho, pois a formação do pescador artesanal individual se dá em meio às relações de interação entre muitos outros pescadores em um processo mediado pelo trabalho. A identidade dos pescadores artesanais, portanto, é uma identidade socializada.

Sob esta perspectiva, pode-se dizer que não existe pescador artesanal individual fora das relações sociais que permeiam o exercício das suas práxis produtivas. Estas relações formam o pescador artesanal como um sujeito coletivo, isto é, uma categoria de trabalhadores. A fala desse entrevistado corrobora essa tesa: "na verdade, eu pesco há muitos tempos atrás, eu acho que desde o começo das atividades a gente é relacionado à pesca" (PESCADOR P7).

A partir disso, cunhados em Dubar (2005), também se pleiteia que o processo de constituição da identidade do ser social pescador artesanal da Colônia Z-16 é resultado de um processo que é, ao mesmo tempo, "individual e coletivo, subjetivo e objetivo, biográfico e estrutural” (p. 136). Noutros termos, a constituição da identidade dos pescadores artesanais sob investigação é um processo mediado pelo trabalho e, por isso, inseparável das relações travadas entre si e com a natureza no interior de sua práxis produtiva.

12 Para Dubar (2005) a identidade é constituída socialmente mediante a utilização de formas de identificação socialmente válidas para atribuir identidades, tanto a si mesmos quanto aos outros. Entendemos que as identidades dos sujeitos sociais (individuais e/ou coletivos) são resultantes, tanto de processos de atribuição por outrem, como de processos de autoidentificação. Por isso, sua definição do que seja identidade leva em consideração aspectos objetivos (meio) e subjetivos (homem): "Desse ponto de vista, a identidade nada mais é que o resultado a um só tempo estável e provisório, individual e coletivo, subjetivo e objetivo, biográfico e estrutural, dos diversos processos de socialização que, conjuntamente, constroem os indivíduos e constroem as instituições (DUBAR, 2005, p. 136). 


\section{O projeto capitalista na Amazônia paraense e metamorfoses na práxis produtiva dos pescadores artesanais}

Entre os anos de 1976 e 1984 foi construída a Usina Hidrelétrica de Tucuruí (UHE-Tucuruí), no rio Tocantins, Estado do Pará ${ }^{13}$. Esta grande obra foi criada "[...] para atender às demandas de grandes projetos industriais que se instalavam na região Norte, como o Complexo Industrial do Alumínio, em Vila do Conde, e a ALBRÁS e ALUNORTE ${ }^{14}$, em Barcarena-PA" (RODRIGUES, 2012, p. 219).

A despeito do objetivo principal da obra e de suas reais consequências, o Estado disseminou um discurso de desenvolvimento regional e, particularmente no contexto do Baixo Tocantins ${ }^{15}$, tal discurso pregava a criação de melhores oportunidades sociais, tais como a geração de emprego e renda e o acesso à energia elétrica pela população local. Assim,

[...] junto às camadas populares da região construía-se o saber de que sua implantação [UHE-Tucuruí] traria o desenvolvimento, implicando melhorias nas áreas da educação, da saúde, da geração de emprego e renda, principalmente para os ribeirinhos (RODRIGUES, 2012, p. 219).

Terminadas as obras, no entanto, os habitantes da Região, sobretudo a população ribeirinha, passou a conviver com os impactos ambientais: "mudanças na qualidade da água, perda do 'controle' da maré devido à alteração do regime do rio, estrangulamento das atividades de pesca e do extrativismo" (SILVA, 2003, p. 02).

Esses impactos, naquele contexto (início da década de 1980), ameaçavam a própria continuidade da sobrevivência dos ribeirinhos nas suas comunidades nativas - sobretudo dos pescadores artesanais, cujo sustento depende historicamente da oferta natural de pescado pelo rio Tocantins. A pesca artesanal, então, entra em um

\footnotetext{
${ }^{13}$ A construção da UHE-Tucuruí integra-se ao plano de desenvolvimento da Amazônia deflagrado pelo Regime Militar que governou o Brasil entre os anos de 1964 e 1985 (RODRIGUES, 2012). Pretendia-se colocar em prática grandes projetos de exploração de riquezas naturais da Amazônia para dá continuidade às políticas de modernização e enriquecimento do país.

${ }^{14} \mathrm{O}$ complexo industrial Albrás/Alunorte localiza-se em Vila do Conde, município de Barcarena, nas proximidades de Belém do Pará. A Alunorte - Alumínio do Norte processa a bauxita para a produção de alumina. A Albrás - Alumínio do Brasil transforma a alumina em alumínio.

${ }^{15}$ A Região do Baixo Tocantins engloba sete municípios: Abaetetuba, Igarapé Miri, Limoeiro do Ajuru, Cametá, Mocajuba, Baião e Oeiras do Pará. Em seu interior está a microrregião de Cametá que é formada pelos municípios de Baião, Cametá, Limoeiro do Ajuru, Mocajuba e Oeiras do Pará. (IBGE, 2010).
} 
período de decadência pela diminuição vertiginosa da oferta natural de pescado, tanto em Cametá como em toda a região do Baixo Tocantins, situação que se mantém até a atualidade, conforme relato do entrevistado a seguir.

Agora por último o matapi não tá dando, é só com malhadeira, isso também não está dando lá essas coisas. Bom, dum certo tempo pra cá, de uns dez anos depois que veio o fechamento da Barragem, ainda se via um peixinho, mas agora tem vez que você sai pro rio, você não arranja pra comer (PESCADOR P2).

De acordo com Silva (2003), essa constatação empírica dos pescadores vem sendo comprovada cientificamente por meio de pesquisas que demonstram uma queda considerável do volume de peixe capturado à jusante ${ }^{16}$ da Barragem. Conforme destaca a autora, "os dados sobre as capturas das pescarias comerciais mostram que, se em 1981 a produção pesqueira atingiu 900t/ano, em 1998, a produção caiu para 492 t/ano, uma queda relativa de aproximadamente 54,3\%" (SILVA, 2003, p. 13-14).

As entrevistas realizadas nos mostram que os rios cametaenses sempre foram abundantes em termo de reprodução de pescado de variadas espécies, sendo que os pescadores tinham à sua disposição esse ambiente farto para, a qualquer momento, ir até ele e capturar sua alimentação.

Olha, quando nós era criança ainda, uns 14, 15 anos, aqui era peixe e camarão que você não vencia. Camarão, chegava a zoar na beira do aningal ${ }^{17}$, a gente ia lá, tinha uma rede de fio aqui que a gente comprava no Abaeté e a gente tinha uma. Aí nós ia, chegava na touceira da aningueira e cercava. E agora a gente passava pra dentro, nós vinha tocando, tocando e quando suspendia a rede vinha o camarão, vinha pescada, vinha tucunaré, o jacundá, vinha tudo lá no meio (PESCADOR P4).

\footnotetext{
${ }^{16}$ Tudo o que está abaixo de ponto de referência, ao longo do curso do rio até à foz, diz-se que se situa "a jusante" (águas abaixo), enquanto tudo que se situa acima, diz-se que se situa "a montante" do mesmo ponto. De acordo com Silva (2003), o barramento do rio Tocantins configurou duas realidades distintas: a área situada a montante da barragem apresentou um aumento da produção pesqueira, ao passo que à jusante, a realidade é essa que estamos discutindo, qual seja a diminuição do pescado. Em relação à UHE-Tucuruí, na área à jusante inclui-se dinâmicas ribeirinhas pertencentes a municípios como Cametá, Baião e Mocajuba.

${ }^{17}$ Aningal é a paisagem característica das margens dos rios do município de Cametá, cuja incidência da aningueira é alta. Trata-se de uma planta adaptada às condições de alagamento da terra onde se encontra e, por isso, mesmo é comum sua presenta nas paisagens das praias e pequenas ilhas fluviais.
} 
Em acordo com Rodrigues (2012), compreende-se a UHE-Tucuruí como legítimo representante do projeto capitalista na região do Baixo Tocantins não só por assegurar a alimentação, com energia elétrica, da infraestrutura necessária à ampliação da acumulação de capital, mas também por promover a desarticulação de um modo de produção da existência humana que não se enquadrava historicamente no circuito de produção e acumulação de capital. O trabalho da pesca constituía, em termos marxianos, um elemento de identificação dos pescadores como produtores independentes, "[...] que exercem seus trabalhos artesanais ou cultivam a terra de modo tradicional" (MARX, 2013, p. 579), isto é, que produzem de forma não subordinada diretamente patrão.

Num contexto natural de abundância de pescado na região, conforme depoimento do entrevistado Pescador P4, a pesca se efetivava da seguinte maneira: "a gente tapava o igarapé e aí a gente só tirava o peixe graudão para gente comer, porque a gente não tinha pra quem vender".

Em primeiro lugar, vê-se a constituição de um elemento de identificação pautado no mutualismo ${ }^{18}$ entre homem e natureza, pois a abundância permitia que os pescadores artesanais operassem uma pesca que não ameaçava a continuidade da reprodução das espécies, na medida em que era possível selecionar o tamanho do pescado capturado.

Em segundo lugar, daquela abundância de pescado decorria uma atividade pesqueira voltada para a satisfação das necessidades de alimentação do pescador, isto é, tratava-se de uma produção de valores de uso, na perspectiva posta por Lukács (2013), para o qual "[...] o valor de uso nada mais designa que um produto do trabalho que o homem pode usar de maneira útil para a reprodução de sua existência" (p. 44).

Para o capitalismo, essa forma de produção e sociabilidade é vista como mais um obstáculo que deve ser superado em nome do progresso, leia-se: expansão do capital. Nas palavras de Foster (2011, p. 90), "para manter sua riqueza sob esse sistema, o capitalista deve continuar a busca para estendê-la", sendo assim,

\footnotetext{
${ }^{18}$ Para categorizar esse elemento de identidade resultante da relação pescador-rio, a qual estamos chamando de elemento de identidade pautado no mutualismo, esse último termo é por nós tomado emprestado da biologia, onde designa "relações ecológicas interespecíficas, que resultam em benefício para todos os organismos participantes" (ELIAS, et. al., 2007, p. 253).
} 
prossegue o autor, se "recusa em aceitar qualquer barreira absoluta para seu avanço, que [são] tratadas como meras barreiras a serem superadas".

O que se observa, ao analisar esse processo de desestruturação da pesca na Região, é o adentramento da lógica de reprodução sociometabólica do capital nessa região da Amazônia Paraense. Num breve exame histórico, observamos a similitude desse processo à expropriação das terras dos camponeses europeus em benefício do estabelecimento do agronegócio, num contexto de transição do modo de produção feudal para o capitalista.

[...] os produtores camponeses, especificamente na Inglaterra, foram expropriados, criando, de um lado, uma classe de fazendeiros arrendatários capitalistas sujeitos aos imperativos do mercado e, de outro, um proletariado de trabalhadores agrícolas obrigados a vender sua força de trabalho em troca de salário (WOOD, 2011 p. 133).

Naquele contexto temporal destacado por Wood (2011), tratava-se da expulsão do camponês de suas terras, onde produziam a subsistência, em função do estabelecimento do agronegócio. Já no contexto de construção da Barragem de Tucuruí, trata-se da expulsão do pescador ribeirinho de seu ambiente natural e histórico de produção da existência em proveito da utilização da natureza (água) para produção de energia elétrica conforme interesse do capital. Em ambos os casos a vida e a forma de sociabilidade dos habitantes nativos são colocados em segundo plano perante a demanda do capital pelos seus recursos naturais.

Verificou-se que os interesses do capital se tornaram incompatíveis com uma perspectiva de sociabilidade que coloca os seres humanos em primeiro lugar, pois a vida em sociedade, sob o capitalismo, é regida pelas necessidades de reprodução constante do capital, ainda que para isso seja necessário promover a precarização das condições de vida e trabalho dos seres humanos, como é o caso ao qual estão sujeitados os pescadores artesanais da Z-16.

Com apenas uma investida (construção da UHE-Tucuruí) o capital consegue um duplo objetivo: as condições infraestruturais para exploração produtiva dos recursos minerais da Amazônia e a penetração de relações mercantis na dinâmica social de uma população que vivia sob relações de produção diversa da forma capitalista de produção e distribuição da riqueza. 


\section{Ressignificação da práxis produtiva e seus desdobramentos para o processo de constituição da identidade do ser social pescador artesanal}

Com os impactos ambientais decorrentes da construção da UHE-Tucuruí, os pescadores precisaram objetivar alternativas produtivas à pesca extrativista. Assim, o manejo de açaizais transforma-se em uma das principais atividades produtivas do pescador artesanal nesse novo contexto.

A coleta do fruto de açaí integra historicamente a práxis produtiva dos pescadores artesanais que têm no vinho desse fruto, no pescado e na farinha de mandioca a base cultural de alimentação (SILVA, 2003). Até o estabelecimento do quadro ambiental de escassez de pescado na região, contudo, a coleta do açaí era uma atividade de caráter extrativista, pois o açaizeiro é uma palmeira nativa dessa região da Amazônia e, assim, produz naturalmente com facilidade o fruto.

A diminuição da produção da pesca artesanal e a necessidade de se comprar os bens necessários a sobrevivência do pescador fez com que a produção do açaí passasse a se destinar para a comercialização: "este produto tem experimentado nos últimos anos uma grande expansão/aceitação no mercado externo regional, nacional e global" (CORRÊA, 2016, p. 01).

Nesse sentido, destaca-se a fala do entrevistado Pescador P7: "não vou dizer que a gente se sustenta só da pesca que não sustenta, mas uma parte do tempo é sim. O outro trabalho que a gente faz é o açaí tempo da safra que é o que ajuda a gente".

Nesse cenário, observa-se a constituição de um elemento neoextrativista de identidade, pois a diminuição de pescado na região acarretou que a produção do açaí como coleta de recursos naturais tivesse que ceder lugar ao manejo dos açaizais, dada a necessidade de se aumentar a produtividade.

[...] o extrativismo apenas como coleta dos recursos naturais vem deixando de ocorrer no caso do açaí na região estudada. Pode-se ainda utilizar os termos neoextrativismo ou agroextrativismo para definir esse momento de transformação, onde se pratica o cultivo e não apenas se extrai os recursos da natureza (CORRÊA, 2016, p. 07). 
A prática do manejo decorrente dessa exigência de intensificação da produção do açaí como valor de troca é descrita nos relatos do entrevistado Pescador P4: "mês de novembro em dei por terminado o açaí do nosso terreno pra fazer o manejo numas árvores que estavam muito altas".

Nesse contexto, ocorre a produção de saberes do trabalho ${ }^{19}$ de manejo pelos pescadores artesanais, cuja identidade se metamorfoseia após a construção da Barragem de Tucuruí com a emergência de um elemento de identidade que permite reconhecer o pescador artesanal como pescador-lavrador ${ }^{20}$.

\begin{abstract}
Passamos a um novo momento onde os açaizais passam a ser manejados, onde ocorre os desbastes das touceiras, a retirada de árvores improdutivas, deixando de 3 a 5 estipes em cada touceira, além da retira de outras árvores de menor valor comercial, raleando a vegetação, para o controle de luz no açaizal (CORRÊA, 2016, p. 07).
\end{abstract}

Em termo de comercialização, a pesquisa constatou que, além da venda nas feiras municipais da Região, a produção do açaí destina-se atualmente à exportação, quando da compra do açaí por Agroindústrias, conforme corrobora o depoimento do entrevistado Pescador P2: "agora tem umas firmas que tá comprando, que leva aí pra fora, mas nós vende aí na cidade de Cametá, Mocajuba, Baião. Mas tem o comprador específico que vai comprar de nós lá no porto".

A venda do açaí para exportação, a nosso ver, facilita a penetração da lógica mercantil do sistema capitalista na vida do pescador artesanal da Z-16. Esse processo constitui-se em um dos exemplos mais categóricos que ajudam a explicar a intensificação da metamorfose da identidade desses pescadores: negam-se os elementos de identidade que caracterizam os pescadores como produtores independentes, para afirmar-se outros elementos identitários próprios do modo de produção capitalista - como a troca de mercadorias - e, assim, intensificar o processo de proletarização da identidade dos pescadores artesanais.

\footnotetext{
${ }^{19} \mathrm{Em}$ acordo com Franzoi \& Fischer (2015, p. 148), "entendemos saberes do trabalho como aqueles produzidos, mobilizados e modificados em situação de trabalho".

${ }^{20}$ Pescador-lavador é quem detém os saberes da pesca e do trabalho agrícola e exerce ambas as atividades concomitantemente. No caso dos pescadores artesanais da Colônia Z-16, a identificação como pescador-lavrador, é uma metamorfose da identidade do pescador artesanal imposta pela construção da hidrelétrica de Tucuruí.
} 
A comercialização do açaí revela-se como uma estratégia do capital para inserção do pescador artesanal do seu ciclo produtivo de expansão. A produção de açaí, nesse aspecto, transforma-se em produção capitalista, ainda que, à primeira vista, esse caráter capitalista não se expresse substancialmente devido apresentarse em imbricação com a economia familiar. Sobre esse fenômeno, Marx (2013) argumenta que "[...] certas formas híbridas [de produção capitalista] são reproduzidas aqui e ali na retaguarda da grande indústria, mesmo que com uma fisionomia completamente alterada" (p. 579).

Do ponto de vista do pescador, a produção do açaí termina ao vender para o atravessador. $\mathrm{Na}$ aparência, trata-se de uma produção de subsistência, mas do ponto de vista do capital trata-se de uma produção de mercadorias.

[...] ele quer produzir valor de uso que tenha valor de troca, isto é, um artigo destinado à venda, uma mercadoria. Em segundo lugar, quer produzir uma mercadoria cujo valor seja maior que a soma do valor das mercadorias requeridas para sua produção, os meios de produção e a força de trabalho, para cuja compra ele adiantou seu dinheiro no mercado. Ele quer produzir não só um valor de uso, mas uma mercadoria; não só valor de uso, mas valor, e não só valor, mas também mais-valor (MARX, 2013, p. 263).

Nesses moldes de produção de mercadorias, a produção de açaí opera a subsunção formal do trabalho do pescador artesanal ao capital. Quer dizer, apesar de ser o capital quem lucra com essa produção, é o pescador artesanal quem detém os conhecimentos, as técnicas e o ritmo da produção do açaí. Trata-se de uma subsunção do trabalho nos moldes em que ocorria nas oficinas do estágio inicial do capitalismo, nas quais o capital investido era de um capitalista, mas as técnicas e todo o processo de produção de mercadorias estava sob controle dos trabalhadores.

Essas primeiras oficinas eram simplesmente aglomerações de pequenas unidades de produção, refletindo pouca mudança quanto aos métodos tradicionais, de modo que o trabalho permanecia sob imediato controle dos produtores, nos quais estavam encarnados 0 conhecimento tradicional e as perícias de seus ofícios (BRAVERMAN, 1974, p. 61).

Ademais, esse processo de comercialização do açaí constitui um elemento de identificação que imprime um caráter fetichizado à identidade dos pescadores 
artesanais da Colônia Z-16, na medida em que a relação de troca que se estabelece entre pescador artesanal e as agroindústrias não se apresentam como uma relação entre produtores de mercadorias, mas entre as próprias mercadorias, ou seja, açaídinheiro.

Marx (2013), analisou esse processo como fetichismo das mercadorias, isto é, o fato de a mercadoria assumir, nas relações de troca, uma objetividade fantasmagórica com poder de trocar-se entre si e determinar a vontade humana. Nesse processo, as mercadorias se humanizam e os homens se coisificam.

\begin{abstract}
A estes últimos, as relações sociais entre seus trabalhos privados aparecem como aquilo que elas são [na aparência], isto é, não como relações diretamente sociais entre pessoas em seus próprios trabalhos, mas como relações reificadas entre pessoas e relações sociais entre coisas (MARX, 2013, p. 148).
\end{abstract}

Tendo o capital a teleologia de reduzir ao máximo possível, por meio dos impactos da UHE-Tucuruí, a autonomia dos pescadores artesanais no que diz respeito à produção da existência, coloca a pesca extrativista em vias de desaparecimento e leva o pescador a intensificar a produção do açaí. No longo prazo, o objetivo do sistema do capital é "[...] a subsunção do produtor a um ramo exclusivo da produção, [e] a supressão da diversidade original de suas ocupações é um momento necessário do desenvolvimento" (MARX, 2013, p. 556).

No contexto dos pescadores artesanais o capital pretende que o açaí seja a única mercadoria que o pescador disponha para conseguir no mercado, por meio da sua venda, a sobrevivência. Então, será a mercadoria (açaí) quem se tornará o sujeito perante um homem-objeto (pescador), pois aquela tornar-se-á capaz de determinar a existência deste: se essa mercadoria tiver no mercado valor suficiente para conseguir para ser trocada pelos bens dos quais o pescador necessita para sobreviver, este sujeito terá uma vida razoável. Caso contrário, viverá em dificuldades.

Por outro lado, os pescadores artesanais não se mostram passivos a essa teleologia do capital, mas objetivam outras alternativas de modo a não se tornarem reféns da produção de uma mercadoria específica, tal como o açaí. É nessa perspectiva que destacamos a criação dos Acordos de Pesca, cujo objetivo principal 
é reorganizar a atividade pesqueira artesanal sob uma lógica semelhante àquela aplicada na produção do açaí, isto é, de manejo dos recursos pesqueiros.

Se a gente não procura fazer esse tipo de Acordo de Pesca, aqui era um rio que você andava daqui pra boca não encontrava o peixe. Olha, até hoje em dia você pode olhar aqui, se descer um taleiro aí nesses poços tudo aí tem mapará. O peixe que mais dá aqui pra nós é o mapará. (PESCADOR P4).

Nas comunidades onde existem os Acordos, os relatos dos entrevistados atestam a ocorrência de um processo de recuperação da incidência de espécies pesqueiras, cuja reprodução nessa região foi quase que impossibilitada, dada as mudanças experimentadas pelo hábitat fluvial após o barramento do rio Tocantins.

\begin{abstract}
Aí veio esse peixe e encheu de tudo quanto foi qualidade. Aí foi, foi, foi, e o pessoal gostavam que quando a gente pegava o peixe a gente repartia com tudo. E hoje ainda existe essa preservação, ela tá mais ou menos com uns 30 anos já que já existe (PESCADOR P4).
\end{abstract}

A criação dos Acordos de Pesca caminha junto a um processo de metamorfose da identidade dos pescadores artesanais: em períodos anteriores à construção da UHE-Tucuruí, do trabalho da pesca em um contexto de abundância, decorria uma perspectiva de identificação dos pescadores artesanais como sujeitos extrativista-coletores. Após os impactos dessa Barragem, contudo, a necessidade de manutenção da atividade pesqueira, que leva a criação dos Acordos de Pesca, está no fundamento do elemento de identificação "neoextrativismo", dada a nova configuração do trabalho da pesca artesanal, agora baseado no manejo dos recursos pesqueiros.

Os Acordos de Pesca expressam a luta de classes, entre interesses antagônicos de capital e trabalho, que passa a configurar o mundo do trabalho da pesca artesanal cametaense após a construção da Barragem. Por um lado, o capital nega a identidade coletiva, socializada, produzida nas relações constitutivas da práxis produtiva. Assim, interfere negativamente no ciclo de reprodução natural das espécies e impõe ao trabalhador da pesca um "esvaziamento de elementos que o constroem enquanto pescador, partícipe de coletivo de sujeitos que se identificam por ações similares no campo do trabalho" (RODRIGUES, 2012, p. 222). Por outro 
lado, os pescadores antagonizam-se ao capital, construindo alternativas que garantam a continuidade da pesca como a práxis produtiva estruturante de sua identidade.

Contudo, os Acordos de Pesca não estão alheios à influência da lógica capitalista. Sendo a economia mercantil a forma hegemônica de estruturação das relações sociais no capitalismo, as formas alternativas de produção estão sujeitas à influência ideológica do capital. Sabe-se que

[...] a ideologia e as relações sociais de produção formam um todo dialético, ou seja, não estabelecem simples relação de complementaridade, mas uma união de contrários. Por mais elaborada, sofisticada ou eficiente que seja uma ideologia, ela é ainda uma representação mental de certo estágio das forças produtivas historicamente determinadas (IASI, 2011, p. 26).

Para empreendermos essa análise sobre a influência da lógica capitalista nos Acordos, primeiramente é preciso considerar que a captura em larga escala do pescado da área de preservação é realizada nos primeiros dias subsequentes ao término do período do defeso ${ }^{21}$. Essa captura é realizada pelas turmas de pesca sob acordo de repartição firmado entre o proprietário da rede de pesca e a comunidade. Cada uma das partes tem direito a metade do total de pescado capturado.

\begin{abstract}
A nossa base aqui é o seguinte: $50 \%$ é dele [do dono da rede] $50 \%$ é nosso [da comunidade]. Se ele pegar 100 paneiros de mapará 50 é dele e 50 é nosso. Do dele ele faz o que ele quiser e o nosso é pra nós repartir com as famílias que tem e pronto, acabou. Porque a gente espera pra isso (PESCADOR P4).
\end{abstract}

Observe-se que existe uma divisão primária, em que a totalidade da captura é dividida em duas partes iguais entre a comunidade e a turma rede de pesca. Mas também há uma divisão secundária: a metade que coube à comunidade é dividida entre seus membros; a outra metade é dividida entre os membros da turma de pesca.

\footnotetext{
${ }^{21}$ Na região de Cametá, de acordo com Silva (2003), a reprodução da maioria das espécies ocorre na época da subida das águas (novembro e março), correspondendo, aproximadamente ao período chuvoso, denominado regionalmente de "inverno" e, por isso, o período de defeso se estende do início do mês de novembro de um ano até o final do mês de fevereiro do ano seguinte.
} 
Nessa divisão secundária coexistem duas formas distintas de repartição da produção: uma primeira forma é baseada em critérios de divisão igualitária da produção, ou seja, a parcela de pescado que coube à comunidade é dividida igualitariamente entre seus membros; uma segunda forma é baseada em critérios desiguais de repartição.

Nessa segunda forma, trata-se da divisão da produção entre os donos das redes de pesca e os trabalhadores que constituem a mão-de-obra das turmas de pesca: "a gente pesca o mapará, tainha, dourado, apapá, esses peixes aí. Vamos dizer, se eu sair para o rio com uma rede dessas aqui e eu fazer cinco mil reais, eu divido no meio: eu tiro a metade pra rede e a metade eu dou para os trabalhadores" (PESCADOR P6).

Uma turma de pesca geralmente é constituída de 20 a 25 pescadores que realizam as várias funções necessárias à captura do pescado: os pilotos, o taleiro, o mergulhador, etc. Os $50 \%$ do total da captura que coube à turma de pesca não é subdividido igualmente entre os trabalhadores, pois a propriedade da rede permite ao dono se apropriar, sozinho, de metade do pescado que coube à turma. A outra metade dos $50 \%$ da captura que coube à turma é repartida entre os trabalhadores que, efetivamente, realizam a pesca. Quer dizer, o dono da rede fica com $1 / 4$ da produção total do Acordo, ao passo que a todos os trabalhadores da turma cabe também $1 / 4$ da totalidade do pescado capturado, mas esse $1 / 4$ deve ser repartido entre aqueles 20 a 25 pescadores.

Se isolarmos apenas a relação de produção e troca estabelecida entre o dono da rede e os pescadores trabalhadores da turma, é possível visualizar que se trata de relações estabelecidas sob a lógica do modo de produção capitalista. O dono da rede da rede exerce o papel do patrão (capitalista), dono dos meios de produção, ao passo que os pescadores que compõem a turma de pesca funcionam como trabalhadores assalariados, pagos com dinheiro ou parte da produção.

Essa forma de relação de produção revela-se como um elemento de identidade de consentimento ao capital e reitera o processo de proletarização da identidade do pescador artesanal ao disseminar na sociabilidade dos pescadores artesanais da Colônia Z-16 a lógica capitalista de relações sociais assentada na venda da capacidade de trabalho e na forma-mercadoria. 
A ideologia mercantil naturaliza, em termos gramscianos, um senso comum, isto é, "formas aparentes de o homem entender a realidade, sem ainda perscrutar as bases materiais que a explicam em sua essência" (RODRIGUES, 2012, p. 228), que referendam a hegemonia da lógica de apropriação desigual da riqueza socialmente produzida.

Por outro lado, a divisão da parcela da produção que coube à comunidade sob Acordo obedece aos critérios de repartição igualitária da produção.

\begin{abstract}
Mas até então o povo vem achando bom, por uma maneira que se você pegar 10 paneiros de mapará num Acordo desse, a gente tem que repartir por tudo, então tudo participa, é bom por isso. Então, se tocar 50 peixes toca pra mim, toca pra um que mora lá nas cabeceiras, sendo daqui do setor pra tudo toca. Então por isso que eu acho que vem dando certo (PESCADOR P4).
\end{abstract}

Trata-se de um processo de distribuição da riqueza social fora dos padrões capitalistas de produção socializada e apropriação privada da riqueza, com base nos critérios de propriedade que colocam a maior parcela da riqueza socialmente produzida nas mãos dos proprietários dos meios de produção. A repartição da produção dos Acordos entre a comunidade obedece aos critérios da propriedade social dos meios de produção e revela-se como um importante elemento de identidade com base no trabalho associado, ao contestar

[...] outras dimensões do sistema produtor de mercadorias e criam soluções para a desmercantilização. Isto pode ser visto nas tentativas de produção de valores de uso, com graus crescentes de controle social [...] [para] gerar trabalho e renda no local das habitações (NOVAES, 2013, p. 74)

Sabendo que "a distribuição os reparte [os produtos do trabalho] segundo leis sociais" (MARX, 2011, p. 44), os Acordos de Pesca constituem um elemento de identidade de negação-consentimento ao capital, pois ora assentam-se numa distribuição igualitária da riqueza, ora em parâmetros de distribuição orientados com base em relações de propriedade.

Ademais, o capital, por meio dos impactos da UHE-Tucuruí, impõe ao pescador em processo de reconfiguração de suas atividades produtivas, a 
emergência de elementos identitários que imprimem um caráter contraditório à identidade desses sujeitos.

Ele [mapará] tem uma época que eu pego aqui com a minha rede. Agora o mapará ele já está de baixada, já tá indo. Ele vai até no Mandií, Maracapucu ${ }^{22}$, aí pra baixo e vai embora. Aí pra lá que tem os Acordos de Pesca. Aí tem tempo que nós vamos pra lá trabalhar com o cara que nos manda buscar. (PESCADOR P3).

Assim, há momentos em que, como dono de rede, o elemento de identificação "propriedade dos meios de produção" se sobressai no processo de constituição da identidade dos pescadores; noutros momentos, em decorrência da escassez de peixes nos rios que dificulta a produção de excedente, o elemento "produtor independente" se sobrepõe nesse processo de constituição da identidade: "na malhadeira eu levo meus filhos, mas quando é nessa rede aqui eu tenho que levar 10, 12 homens comigo que se não for esse tanto de homem não trabalha" (PESCADOR P6); há momentos, ainda, em que se observa a sobreposição do elemento de identidade "proletário da pesca" como forma de identificação desses pescadores, mais precisamente quando esses sujeitos se submetem aos trabalhos sob relações de assalariamento nas turmas de pesca.

Nas áreas sob Acordos o elemento de identidade produtor independente predomina na maior parte do tempo, pois para garantir a captura do próximo ano, o trabalho da pesca se volta para fins de subsistência.

\begin{abstract}
Você tem o caniço, você tem a sua linha, você tem seu espinhel onde você põe num lugar onde você acha que vai puxar o dourado, o filhote, até uma arraia. Você bota lá. Você pega sua linha e pega o camarão, você vai procurar o poço, onde é que a pescada tá. Se ela tiver lá você puxa, você tem que puxar 4 ou 5 quilos de pescada. Então todo dia o pescador tem que tirar essa quantia de peixe, não é proibido, 5 quilos de peixe o pescador tem que tirar pra sustentar a família dele. (PESCADOR P5).
\end{abstract}

Essa forma de gestão dos recursos pesqueiros nos Acordos revela-se, em termos identitários, como um elemento de identidade pautado no trabalho associado e é uma experiência exemplar que imprime à identidade dos pescadores artesanais

22 Comunidades ribeirinhas situadas na área situada ao norte do município de Cametá que vai em direção ao município de Limoeiro do Ajurú. 
uma configuração de resistência à lógica mercantil da reprodução da existência, pois garante o auto sustento dos pescadores pela produção de valores de uso (pesca de subsistência). Para Novaes (2013), "o trabalho associado é um princípio educativo. Também nos permitem afirmar que estas lutas serão fundamentais para a desalienação do trabalho e ganham traços de lutas anticapital" (p. 76).

Nessa perspectiva, diz-se que os Acordos "cumprem um papel mais qualitativo do que quantitativo" (NOVAES, 2013), em termos de transformação social: por si sós não têm o poder de superar o capital, mas é um modelo de organização do trabalho que prova concretamente que é possível uma forma de produção emancipada das relações mercantilizadas. Nesse caso, os Acordos expressam-se como a reafirmação do homem à terra, aos elementos da natureza, à moradia, ao trabalho, à cultura, às relações interpessoais, ou seja, constitui elementos que concorrem para a reestruturação de sua identidade histórico-social alterada pelos impactos da construção da UHE-Tucuruí.

Essa forma de objetivação como resistência, também perpassa pela manutenção de formas de relações sociais que consubstanciam a constituição de elementos de identidade pautados na solidariedade e no companheirismo e que mantém viva uma cultura formada nas relações do trabalho da pesca num tempo em que o pescado ainda era abundante na Região.

Destaca-se, nessa perspectiva, a tradição de se separar parcela de cada captura para divisão entre os pescadores que acompanham os bloqueios dos cardumes: "naquele tempo, você fazia tapagem, não carecia de você comprar, você ia no beiço da tapagem, o dono da tapagem lhe dava pra você comer, tudo esses tipos de peixe: curimatá, mapará" (PESCADOR P2).

O pescado que o dono da tapagem distribuía para as pessoas no beiço da tapagem, em tempos de fartura, é o que os pescadores artesanais chamam de boia, pois se trata de uma quantia de pescado doada para a alimentação de outros pescadores. Essa tradição vem sendo alimentada no cotidiano do trabalho da pesca e resiste até os dias atuais: "ontem eu peguei 8 paneiros de mapará, aí como é já reserva né, aí eu divido com a reserva, tirei um paneiro pra boia e resto eu mandei vender" (PESCADOR P3).

Por mais que o capital tente impor sua lógica de mercantilização das relações sociais na pesca, pois num quadro de escassez de pescado a tendência é 
que a totalidade da produção seja destinada à venda, os pescadores artesanais resistem à coisificação as relações sociais e mantêm uma prática cultural que humaniza o trabalhador. "A gente faz o seguinte: se tocar os dez paneiros pra gente, a gente vende 8 e tira 2 pra distribuir como boia. É esse o sistema assim que eu trabalho" (PESCADOR P1).

A partir dessa práxis de resistência constituem-se dois elementos de identidade que recusam a identidade atribuída (DUBAR, 2005) pelo capital:

Um primeiro, que chamamos de elemento residual de identidade, devido sua constituição ter como base uma cultura residual (WILLIAMS, 2011) que expressa a resistência de uma forma de produção pré-capitalista (produtores independentes) em que o capital não conseguiu ainda se apoderar por completo.

Por "residual" quero dizer algumas que experiências, significados e valores que não podem ser verificados ou não podem ser expressos nos termos da cultura dominante são, todavia, vividos e praticados como resíduos - tanto culturais quanto sociais - de formações sociais anteriores (WILLIAMS, 2011, p. 56).

E um segundo, que surge em contrariedade ao capital, e que o chamamos de elemento emergente de identidade (WILLIAMS, 2011) pautado em novos significados e valores, novas práticas, novos sentidos e experiências [que vão] sendo continuamente criados" (p. 57). Tratam-se de experiências que comprovam empiricamente que outras formas de produção e distribuição da riqueza pautadas na solidariedade e no companheirismo, para além do capital, são possíveis.

\section{Considerações}

Com base nas reflexões empreendidas no texto, conclui-se que, no plano ontológico, a identidade de ser social pescador artesanal é constituída no seu processo de socialização mediada pelas relações de trabalho. No plano históricoconcreto, o processo de constituição de identidade entre os pescadores artesanais da Colônia Z-16 ocorre em meio a uma materialidade de disputa entre capital e trabalho pelo controle da práxis produtiva.

Por meio dos impactos ambientais decorrentes da construção da UHETucuruí, o capital se utiliza de formas de identificação fundamentadas na forma- 
mercadoria para atribuir elementos de identidade pautados na mercantilização das relações sociais, no individualismo, na sobreposição do valor de troca em relação ao valor de uso, na exploração da força de trabalho e na busca incessante de lucro. Tratam-se de artimanhas para impedir que os pescadores artesanais vislumbrem outras formas de relações sociais para além da troca de mercadorias e sejam inseridos na lógica do sistema capitalista.

Por outro lado, vivenciando a precarização de suas condições de trabalho e a desestruturação da pesca extrativista, os pescadores artesanais negam a perspectiva de identidade atribuída pelo capital e iniciam um processo de fortalecimento enquanto fração de classe.

Ressignificam, então, sua práxis produtiva e sua identidade, na medida em que transformam a pesca artesanal e a coleta do açaí em atividades de manejo de recursos naturais em detrimento da prática extrativista como eram desenvolvidas no período anterior à Hidrelétrica.

Embora nos interstícios dessas alternativas a lógica de mercantilização da produção e da distribuição da riqueza se façam presentes, o capital ainda não consegue controlar a totalidade dos processos de trabalho dos pescadores.

No interior da práxis produtiva, além da constituição de elementos de identidade de resistência, os pescadores ensaiam formas emancipadas de produção e distribuição da riqueza, tal como ocorre na gestão coletiva e repartição igualitária do pescado nos Acordos de Pesca, constituindo, assim, sua identidade a partir de uma perspectiva contra hegemônica.

\section{Referências}

BARRA, José Domingos $F$. A relação trabalho e educação no contexto dos acordos de pesca em Cametá/PA: uma alternativa econômica ou uma prática de resistência? 114f. Dissertação (Mestrado em Educação) - PPGED/ICED/UFPA, Belém, 2013.

BRAVERMAN, Harry. Trabalho e capital monopolista: a degradação do trabalho no século XX. 3 ${ }^{\underline{a}}$ Ed. Rio de Janeiro: Zahar Editores S.A., 1974. 
CORRÊA, Rosivanderson B. A produção do açaí na Amazônia Tocantina: perspectiva para o desenvolvimento regional. 12 p. Anais do XVIII Encontro Nacional de Geógrafos. São Luis, MA, 2016.

DUBAR, Claude. A socialização: construção das identidades sociais e profissionais. São Paulo: Martins Fontes, 2005.

ELIAS, Larissa G. et al. Efeito de vespas não-polinizadoras sobre o mutualismo Ficus - vespas de figos. Iheringia, Sér. Zool., Porto Alegre, v. 97, n. 3, p. 253-256, set. $2007 . \quad$ Disponível em: <http://www.scielo.br/scielo.php?script=sci_arttext\&pid=S0073$47212007000300006 \&$ Ing=pt\&nrm=iso $>$. Acesso em: 08 jun.2018.

FOSTER, John Bellamy. A ecologia da economia política marxista. Tradução de Pedro Paulo Bocca. Revista Lutas Sociais, São Paulo, n.28, p.87-104, 1ํㅗ sem. 2012.

FRANZOI, Naira L. \& FISCHER, Maria C. B. Saberes do trabalho: situando o tema no campo trabalho-educação. Revista Trabalho Necessário, pp. 147-172, ano 13, № 20, 2015. ISSN: 1808 - 799X. Disponível em: <http://www.uff.br/trabalhonecessario>. Acesso: 12 abr. 2018.

FURTADO, Gislane D. No lar, nas águas, na vida: práticas e saberes em comunidades ribeirinhas- Cametá-Pa. 148f. Dissertação (Mestrado em Educação e Cultura) - PPGEDUC/UFPA, CAMETÁ, 2017.

IASI, Mauro L. Ensaios sobre consciência e emancipação. $2^{\frac{a}{a}}$ ed. São Paulo: Expressão Popular, 2011.

IBGE. Cametá. Disponível em: <https://cidades.ibge.gov.br/brasil/pa/cameta/panorama>. Acesso em: 12 abr. 2018. KOSIK, Karel. A dialética do concreto. $2^{\underline{a}}$ ed. Rio de Janeiro: Paz e Terra, 1976. LUKÁCS, György. Introdução a uma estética marxista: sobre a categoria da particularidade. Rio de Janeiro: Civilização Brasileira, 1978.

Para uma ontologia do ser social l. 1를. Edão Paulo: Boitempo, 2013. 
. Para uma ontologia do ser social II. São Paulo: Boitempo, 2012.

Prolegômenos para uma ontologia do ser social: questões de princípios para uma ontologia hoje tornada possível. São Paulo: Boitempo, 2010

MARTINS, Egídio. Pescadores artesanais da Colônia Z-16: relações de produção formação e práxis política. 209f. Tese (Doutorado em Educação) PPGED/ICED - UFPA, Belém, 2017.

. Trabalho, educação e movimentos sociais: um estudo sobre o saber e a atuação política dos pescadores da Colônia Z-16, no município de Cametá 114 f. Dissertação (Mestrado em Educação) - PPGED/ICED/UFPA, Belém, 2011.

MARX, Karl. Grundrisse: manuscritos econômicos e 1857-1858: esboços da crítica da economia política. São Paulo: Boitempo, 2011.

O capital: crítica da economia política: Livro I: o processo de produção do capital. São Paulo: Boitempo, 2013.

NOGUEIRA, Oscar L. Açaí. Belém, PA: Embrapa Amazônia Oriental, 2005.

NOVAES, Henrique T. O trabalho associado como princípio educativo e a educação escolar: notas a partir das fábricas recuperadas brasileiras e argentinas. Revista HISTEDBR On-line, no 54, p. 70-88, dez2013 - ISSN: 1676-2584. Disponível em:<https://periodicos.sbu.unicamp.br/ojs/index.php/histedbr/article/view/8640169>. Acesso em: 15 mar. 2018.

PÁDUA. Elisabete M. M. de. Metodologia da pesquisa: abordagem teóricoprática. $17^{\mathrm{a}}$ ed. Campinas, SP: Papirus, 2012.

POMPEU, José C. V. Saberes do trabalho e formação de identidade de pescadores artesanais no município de Cametá-Pará. 159f. Dissertação (Mestrado em Educação e Cultura) - PPGEDUC/UFPA, CAMETÁ, 2017.

RODRIGUES, Adenil A. Juventude, trabalho e educação: a formação da identidade pescadora dos jovens da Colônia de Pescadores Artesanais Z- 16 de 
Cametá-PA. 153f. Dissertação (Mestrado em Educação) - PPGED/ICED/UFPA, Belém, 2016.

RODRIGUES, Doriedson do S. Saberes Sociais e Luta de Classes: um estudo a partir da Colônia de Pescadores Artesanais Z-16 - Cametá-Pa. 335f. Tese (Doutorado em Educação) PPGED/ICED - UFPA, Belém, 2012.

SILVA, Maria das G. O reordenamento sócio-territorial na área da UHE-Tucuruí: o caso da pesca no Baixo Tocantins (Pará/Brasil). In.: Anais do XI Congresso Brasileiro de Sociologia, GT10 - Relações socais e meio ambiente. ISSN: 22366636. Campinas, SP: 2003.

VÁZQUEZ, Adolfo S. Filosofia da Práxis. $2^{\underline{a}}$ ed. Buenos Aires: CLACSO; São Paulo: Expressão Popular, Brasil, 2011.

VIGOTSKY, L. S. A formação social da mente: o desenvolvimento dos processos psicológicos superiores. $7^{\mathrm{a}}$ ed. São Paulo: Martins Fontes, 2007.

WILLIAMS, Raymond. Cultura e materialismo. São Paulo: Editora Unesp, 2011.

WOOD, Ellen M. Democracia contra capitalismo: a renovação do materialismo histórico. $1^{\text {a }}$ ed. Revista. São Paulo: Boitempo, 2011.

Recebido em: 16 de agosto de 2018. Aprovado em: 04 de outubro de 2018. Publicado em: 22 de novembro de 2018. 